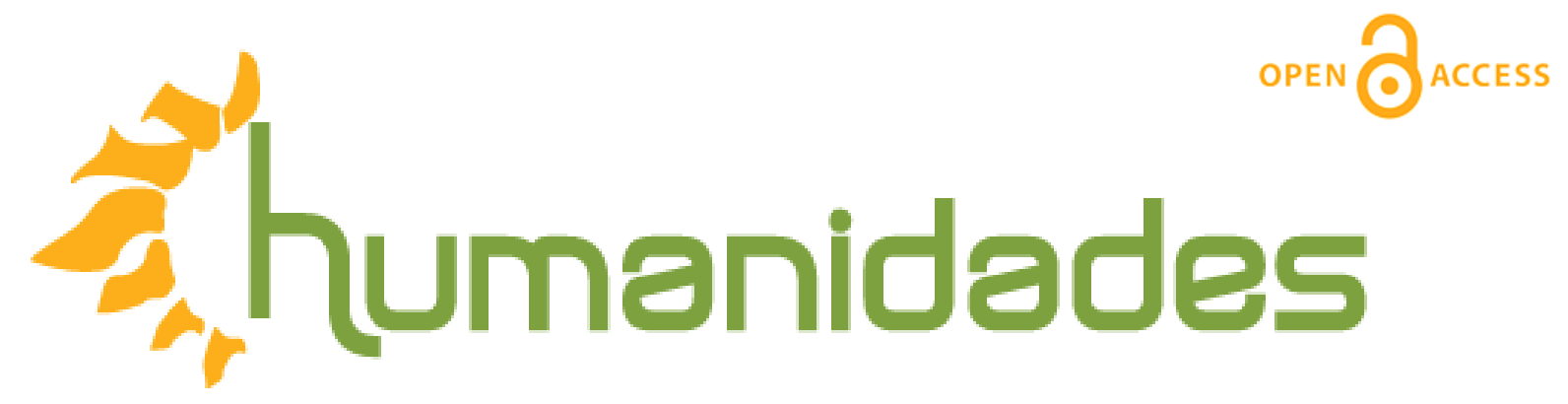

Revista de la Escuela de Estudios Generales, Universidad de Costa Rica

Julio-diciembre, 2016 • Volumen 6, número 2 • EISSN 2215-3934 • pp. 1-16

Recibido: 09-Junio-2016 Aceptado: 5-Septiembre-2016

\title{
Los monstruos en la narrativa de Quiroga
}

DOI: http://dx.doi.org/10.15517/h.v6i2.26740

\section{Óscar G. Alvarado Vega}

Doctor en Estudios de la Sociedad y la Cultura. Profesor en la Escuela de Estudios Generales de la Universidad de Costa Rica.

Correo electrónico: oalvarado100@ gmail.com

Todos los derechos reservados. Universidad de Costa Rica. Esta revista se encuentra licenciada con Creative Commons. Reconocimiento-NoComercial-SinObraDerivada 3.0 Costa Rica.

Correo electrónico: humanidades@ucr.ac.cr / Sitio web: http://revistas.ucr.ac.cr/index.php/humanidades 


\title{
Los monstruos en la narrativa de Quiroga
}

\section{Resumen}

Los monstruos en Quiroga son producto de la febril creación de un escritor que construye, en el devenir de sus personajes, sometidos a un entorno que los asfixia, un mundo de desencanto, de derrota, de dolor, de muerte, de sufrimiento, de sed, de angustia. Leer la narrativa de Quiroga es encontrar a esos monstruos metafóricos que signan la vida difícil e ingrata en ocasiones de cada uno de ellos en ese mundo que los contiene, los limita y les recuerda, a cada instante, su propia pequeñez.

\section{The Monsters in the Horacio Quiroga's Narrative}

\begin{abstract}
The monsters in Quiroga are product of the feverish creation of a writer who constructs, in the happening of his characters, subjugated to an environment that asphyxiates them, in a world of disillusion, pain, death, suffering, thirst, anguish. Reading Quiroga's narrative is finding those metaphoric monsters that point out the difficult and ungrateful life that, sometimes, in each of them, holds, limits and reminds them their own smallness.
\end{abstract}

Palabras claves: Literatura latinoamericana, mitología, cuento, literatura de ficción, estilo literario.
Keywords: Latin American literature, mythology, short stories, fiction, literary style. 
El monstruo es siempre una amenaza al orden establecido, un orden que claramente pasa por el plano de lo "normado" socialmente, desde la perspectiva de lo aceptado o no, de lo legitimado o no.

De acuerdo con esto, y a partir de lo que representa la narrativa de Horacio Quiroga, los monstruos literarios se confirman desde una otredad que "viola" y que atropella los cánones de un mundo en el cual algunos de sus personajes se convierten en verdaderos protagonistas de esa monstruosidad.

Lo cierto es que en Quiroga los temas se anudan a esa monstruosidad. Por ello, el terror, la angustia, la desolación, la muerte, la soledad, el abandono, el fracaso, la derrota, la desesperanza, lo fantástico fantasmagórico, las ambientaciones áridas o cargadas de una majestuosidad que reduce al ser humano, la locura, las alucinaciones y los delirios, entre otros, se convierten en ejes en los cuales se apoya la producción narrativa de un Quiroga que, en sí mismo, carga la tragedia de la vida.

En su narrativa, la selva es seductora, imponente, pero también monstruosa. Su vida es parte del acontecer existencial que luego toma parte en la mayoría de sus relatos. Incluso, los autores que influyen en su narrativa, de los cuales "alimenta" lo que ha de ser su estilo, son maestros en los que también los personajes en ocasiones no escapan al filtro de un mundo cargado de adversidades: Chejov, Poe, Maupassant, Kipling, Dostoievski y Darío. 
En Quiroga confluyen el modernismo, lo terrorífico, lo fantástico y el realismo, con tintes naturalistas, en los cuales la tragedia humana toma lugar preponderantemente. La muerte o asesinato de la hija, la muerte del padre, el hombre que sucumbe a raíz de la mordedura de la serpiente, aquel que cae desplomado a causa de la insolación, el otro que muere accidentalmente al clavarse un machete, el que es devorado por las hormigas y la que cae fulminada a cuchilladas por parte de su hermanos enajenados o desangrada por un insecto gigantesco, son parte de los temas en los que converge una especie de sino trágico para cada ser humano que transita por las páginas de sus relatos.

En sus cuentos, la interiorización de personajes, con sus conflictos existenciales, van marcando el ambiente derrotista que caracteriza a la mayoría. De tal manera, el entorno y la subjetividad de los personajes parecen cruzarse, de forma que dan paso a un ambiente de desolación que comportan sus relatos y que dan paso al pesimismo que se desprende de estos.

Por lo anterior, es claro que las atmósferas, es decir, los entornos y los conflictos internos, tienden a la tragedia y a la derrota. El entorno avasalla al ser humano y lo reduce, tal como se puede encontrar también en los relatos de Carlos Salazar Herrera, en su libro Cuentos de angustias y paisajes.

En Quiroga, el amor termina por convertirse en manifestación frustrada, en una locura sintomática y en una muerte como tema recurrente. De hecho, en un 
texto como Cuentos de amor de locura y de muerte, los monstruos están referidos, en cada uno de los relatos, como una plasmación de la cual se deriva el desencanto, las obsesiones malsanas, la derrota y la desesperanza:

Cuentos de amor de locura y de muerte, refleja igualmente otras características de la obra quiroguiana: el sentido trágico de la vida, la obsesión de la muerte, lo sobrenatural y la naturaleza salvaje son aspectos notorios de sus relatos (Prólogo, 1992, p. 15).

En "La gallina degollada", por ejemplo, la monstruosidad no solo se lee desde la perspectiva asignada a los hermanos, sino también desde sus actos, ejecutados en el plano de la idiotez conferida por el texto:

Todo el día, sentados en el patio de un banco, estaban los cuatro hijos idiotas del matrimonio Mazzini-Ferraz. Tenían la lengua entre los labios, los ojos estúpidos y volvían la cabeza con la boca abierta (Quiroga, 1993, p. 89).

Desde su condición humana se los bestializa, se los despoja de la humanidad que les pertenece. Su anormalidad los convierte en monstruos, sujetos fuera de la normalidad aceptada socialmente; y por ello son insoportablemente soportados por sus padres. El idiotismo conferido, la saliva que les cuelga y que les empapa los pantalones, la incapacidad de expresarse como los demás y su mero acto de simplemente imitar, los va relegando, hasta desnaturalizarlos, "mounstrificarlos". 
Son la vergüenza de los padres, quienes se recriminan por el peso genético que uno u otro pudo haber aportado a la situación de los cuatro hijos.

Los adjetivos que les identifican ante el resto vienen a confirmar la idea de un total rechazo y de una condición que no es la de los otros: sin inteligencia, sin alma, idiotas y babosos, animalizados y engendros.

La relación de los padres se ve deformada por causa de la presencia innegable e indeseada de los cuatro hijos mayores, en tanto que el consuelo de ambos se centra en la hija, la única que escapa a la maldición de sus hermanos. No obstante, un sino trágico rodea el devenir de la familia:

Cuanto más intensos eran los raptos de amor a su marido e hija, más irritado era su humor con los monstruos (Quiroga, 1993, p. 94).

El acto más monstruoso del relato se gesta a partir de la imitación que efectúan los niños, después de haber visto a la cocinera degollar a una gallina. El color de la sangre les resulta atractivo, como cualquier otro color encendido, y encuentran en su hermana la excusa para explorar por sí mismos lo visto durante la mañana. De tal forma, lo fatídico y la muerte toman lugar en el relato y su desarrollo. La muerte de la hija termina por sellar la tragedia que se cierne sobre estos y pone de relieve la monstruosidad que se deduce en la contemplación de la sangre en el piso. 
En otra óptica de lo monstruoso, y no menos aterrorizante, aparece el texto "El almohadón de plumas", texto en el cual el amor idílico de una pareja, compuesta por Jordán y Alicia, termina por convertirse en una pesadilla para la joven esposa, quien cae enferma ante la frialdad del esposo, el cual la ama, pero es incapaz de mostrarlo. La enfermedad se acentúa, los días en cama se aceleran, mientras los delirios terminan por atrapar a Alicia y a la debilidad de su cuerpo; así, las pesadillas, el cansancio y el abatimiento se van haciendo cada vez más fuertes. Luego, en su delirio, ve seres antropomorfos entrar a su habitación. Estos no son más que la figura de Jordán cuando entra a la habitación a mirar a su esposa.

Finalmente, al retirar el almohadón, la empleada y Jordán descubren un insecto monstruoso que vivía en este, el cual sorbió la sangre de la joven mujer hasta matarla. El monstruo, una metáfora en verdad, deriva en el propio Jordán, lo mismo que los delirios de Alicia. El monstruo era el esposo, frío, impasible, lejano, quien, lejos de darle una casa, le otorga una prisión, y termina por reducirla totalmente. La muerte era el camino final.

Los monstruos y la monstruosidad, como fundamentos contra los cuales luchan los hombres y mujeres, o a los que se asimilan finalmente, deambulan por su narrativa. En "Anaconda", por ejemplo, se ubican dos monstruos: los hombres como invasores del mundo de las serpientes y el espacio de la selva como ámbito de vida para estas. De igual forma, una nueva invasión prefigura la 
segunda monstruosidad: la cobra real que pretende convertirse en dominadora de las culebras y serpientes nativas. La lucha en ambos casos desencadena el conflicto y lleva a la disolución de este, en un caso, y a la destrucción casi total de estas, en el segundo.

Las víboras adquieren protagonismo, con características humanas no siempre positivas (antropomorfismo). El choque entre las serpientes y los hombres, y entre ellas mismas, pone de relieve la emergencia de lo que representa el concepto civilización/barbarie y en lo que comporta cada uno de estos semas.

Conflicto entre el hombre y las serpientes (civilización/barbarie). Conflicto entre culturas (serpientes diferentes, a lo interno y hacia lo externo). Anaconda termina por convertirse en personaje principal, vital. Participa en un congreso para tomar resoluciones, para determinar las pautas de enfrentamiento contra el otro, el invasor, el verdadero monstruo.

El tema del empoderamiento es también fundamental, en tanto tiene que ver con el proceso de desencuentro existente entre Anaconda y Hamadrías. Es un choque cultural que tiene como objetivo la imposición de lo externo hacia lo nativo, y el rechazo de lo externo por parte de lo propio, de lo autóctono. 
Se plantea, simbólicamente, la defensa de la vida, de la cultura, del medio, del hábitat y de lo propio. Las serpientes, que se posicionan desde el poder, terminan por sucumbir, mientras el hombre impone su dominio sobre la selva, ejemplificada por los ofidios.

El hombre termina por imponerse, vida y muerte como elementos de desencuentro, la imposibilidad de "diálogo". La naturaleza sucumbe ante un medio invasor, representado por el hombre. Aun así, la relación entre Anaconda y los hombres, los cuales la salvan de la muerte, da paso a una posibilidad de acercamiento, de aprendizaje y de adaptación de dos mundos. El texto no se cierra, sino que se abre a otro texto: "El regreso de Anaconda" ha de ser ese texto.

Se juega con la idea del bien y el mal, como desencuentro inevitable (la cobra y la anaconda como paradigmas de esta lucha). La relación entre otredad y mismidad tiene lugar a lo largo del texto, donde claramente la alteridad se impone por un lado (los hombres, caballos y perro), mientras la mismidad se impone por otro (Anaconda vence a Hamadrías).

La idea de un paraíso profanado viene a tomar lugar en el mundo de la selva. Allí confluyen, no obstante, dos espacios en contradicción: paraíso e infierno. La sobrevivencia permite, sin embargo, la unión de serpientes y culebras, en 
donde la simbología entre la naturaleza contra el "progreso" viene a corromper y a destruir la idea de un espacio paradisiaco.

El sema muerte toma lugar, fundamentalmente, hacia el final del relato, aun cuando es latente a lo largo del texto. El entorno se vuelve terrorífico, amenazante en tanto los hombres van tomando un lugar preponderante, lo mismo que Hamadrías, astuta y engañosa. Lo paradójico es que la propia Anaconda no pertenece al lugar, tal como las otras serpientes. En definitiva, ella es ajena también, pero con la idea de justicia que termina por calar en el espacio en donde se encuentra.

De igual manera, en textos como "La insolación", "El desierto", "El regreso de Anaconda", "El hombre muerto", "A la deriva", "Las moscas", entre otros, las descripciones extensas y minuciosas reiteran la idea de un espacio demoledor que atenta contra el ser humano y lo reduce a la humillación o al aniquilamiento.

La sangre, el dolor y el cansancio dan cuenta de una ambientación en la cual, la mayor parte de las ocasiones, las relaciones desiguales entre el medio y el ser humano propician una batalla en la que el primero manifiesta su derrota como tal. 
La monotonía ahoga a los personajes en algunos relatos, los predispone a una muerte ante la que no tienen salida, como ocurre en "La insolación", con la muerte del viejo ante los ojos de los perros, que antes ven al fantasma de este deambular por el campo.

Los personajes solitarios deambulan por la narrativa de Quiroga, como sujetos desprovistos de un asidero a la sociedad. El delirio de algunos de estos, como en "Los destiladores de naranja", "El desierto" y "El almohadón de plumas", por citar apenas algunos, grafican las existencias en conflicto que estos manifiestan.

Muchos de los personajes son innombrados, lo cual los convierte en símbolos de su propia carencia. Invisibilizados y reducidos se mueven en espacios que los oprimen y los desdibujan. El medio lo oprime, se convierte en un entorno hostil y monstruoso, a pesar de que el ser humano, por sí mismo, es también su propio monstruo.

En algunos casos, incluso, su proceso de abatimiento lo asimila con el medio de manera grotesca. Ejemplo de ello es "Las moscas", donde la muerte del hombre lo convierte luego en un sujeto que "revive" en la mosca, en sus huevos, en la sucesión de esta, en una especie de desdoble, de reaparición del personaje, pero en otra forma. 
El monstruo por sí mismo, en su esencia, puede resultar majestuoso, imponente, de ahí la idea de la selva en la cual convergen lo monstruoso y lo avasallante, así como lo majestuoso en tanto admiración hacia esta. Es lo que ocurre en el relato "El regreso a la selva", a la cual se contrapone la ciudad, como espacio de rechazo, visto negativamente. A pesar de ello, el regreso a la selva pasa por el plano de la imposición del discurso de afuera hacia este espacio vital, en el cual ahora el hombre debe dominar. De nuevo, parece gestarse la imposibilidad de un diálogo.

De igual forma, el enfrentamiento entre ser humano y naturaleza se manifiesta en un relato como "Cacería del hombre por las hormigas", en el cual el depredador por antonomasia resulta depredado. Las hormigas son lo monstruoso, el peligro inminente y la amenaza. El desconocimiento de la selva la convierte en hostil, peligrosa y monstruosa. Es alteridad plena, en un relato en el cual la apertura hacia otro potencial texto, el correr abierto, da margen a la continuación del misterio y el terror.

En "El hombre muerto" la idea de la muerte se vuelve monstruosa en tanto la espera, lo mismo que ocurre en "A la deriva", el cual es de agonía, sin salida, sin escapatoria, mientras el tiempo parece burlarse de los dos hombres, en cada relato, y los mina poco a poco. La angustia que los carcome, mientras la vida parece pasar ante ellos veloz, los sumerge en la noción degradante de su pequeñez ante un entorno que los contiene y los domina por completo. Ese 
entorno es el monstruo ante el cual no tiene posibilidad de enfrentamiento. La selva es el monstruo. La naturaleza, con toda su majestuosidad, es también el infierno que los reduce.

Personajes desgarrados, hombres y mujeres que sufren las vicisitudes de un medio que los agobia. El sufrimiento del padre que, ante su propia muerte, no puede impedir que esta, posteriormente, caiga sobre sus propios hijos, solitarios en ese mundo de selva casi infinito.

Si bien los monstruos circundan la narrativa de Quiroga, lo cierto es que las situaciones propiciadas por ese mundo infernal, que en ocasiones es el entorno selvático, a pesar de la belleza que lo puede caracterizar, de su majestuosidad, del enamoramiento perenne que manifiesta este autor hacia ese mundo, son las principales circunstancias que median en la emergencia de ese mundo siniestro, avasallador e imponente que recuerda a los personajes la pequeñez que los caracteriza.

El sol que devora es monstruoso, el enfrentamiento entre las víboras y los hombres, en medio de la selva, es monstruoso, la insolación también lo es. Así mismo, el delirio y la locura que aprisiona al padre que termina por matar a su propia hija o el padre que no percibe la muerte del hijo en el interior de la selva y luego cree hallarlo y caminar a su lado cuando en realidad camina 
solo, envuelto en alucinaciones; monstruosa es la presencia de la garrapata gigante que succiona la sangre de la recién casada hasta matarla.

Si bien Horacio Quiroga carga con sus fantasmas como escritor y como sujeto, es en sus cuentos donde salen a relucir los verdaderos conflictos que manifiestan el hacer y el quehacer de sus personajes. Sin importar el acercamiento biográfico que se le quiera dar al escritor, en relación con su producción literaria, lo cierto es que ambos son textos, constructos y manifestaciones independientes. No es el autor quien carga con los monstruos; son estos los que emergen en la narrativa, en cada personaje, en los acontecimientos, en las diversas historias que se ubican en la escritura de este uruguayo.

Es por ello que en "La gallina degollada" los acontecimiento en verdad son monstruosos, en la medida en que los hijos y sus problemas mentales, aun cuando niños, acaban con la vida de la propia hermana, en un gesto "inocente" de imitación, mientras gruesos charcos de sangre encuentran la vista horrorizada de ambos padres después de que la pequeña ha sido degollada.

En "Las moscas" la idea de la muerte ronda al personaje, atrapado, con la certeza de que el fin está cerca, inexorable, sin posibilidad de salvación. Monstruosa también la idea de una muerte inminente, con un apego a la vida que ya no tiene más allá. 
Quizás los monstruos en Quiroga devengan de la influencia de Poe en su narrativa, marca del escritor norteamericano de la cual el uruguayo, si bien luego transitó por otras influencias, nunca dejó de lado. Poe ejerce en Quiroga lo que este en algún momento expresó sin tapujos: “Tengo la cabeza llena de Poe". "El tonel de amontillado", influencia también clara del estadounidense, es ejemplo de lo que significa la fuerza de aquel. En este relato, la monstruosa acción de venganza vuelve a ejercerse, solo que ahora de manera inversa. El emparedamiento, el encierro, la oscuridad, la vejación, la venganza, la burla y la risa macabra confluyen para construir el sentido espeluznante que se desprende de tal cuento. El miedo es también una manifestación monstruosa de los peores actos del ser humano.

En definitiva, los monstruos son la forma oscura del acontecer de los personajes. Monstruos físicos, monstruos morales, monstruos degradados, monstruos que degradan. La selva, el hogar, la ciudad y la vida misma son un constructo de monstruos que derivan de los diversos relatos de Quiroga. Leer es encontrar al monstruo y, quiérase o no, interpretarlo y enfrentarse a este. 
Alvarado, O. (2010). El almohadón de plumas y las diferencias sexuales Referencias a partir del falo. San José, Costa Rica: Editorial Perro Azul.

Quiroga, H. (1990). El hombre muerto. Bogotá: Editorial Norma.

Quiroga, H. (1993). El salvaje. Madrid: Editorial Alianza-Losada.

Quiroga, H. (1992). Cuentos. México: Editores Mexicanos Unidos.

Quiroga, H. (1993). Cuentos de la selva. México: Editores Mexicanos Unidos.

Quiroga, Н. (1999). Cuentos de amor de locura y de muerte. México: Editores Mexicanos Unidos.

\section{¿Cómo citar este artículo?}

Alvarado, O. (Julio-diciembre, 2016). Los monstruos en la narrativa de Quiroga. Revista humanidades, 6(2), 1-16. doi: dx.doi.org/10.15517/h.v6i2.26740 